\title{
Major Violations and NCAA 'Powerhouse' Football Programs: What Are the Odds of Being Charged?
}

\author{
K. AleXa OtTO \\ Western Carolina University
}

National Collegiate Athletic Association (NCAA) Division I-A football is the most lucrative sport in all of intercollegiate athletics (Fulks, 2001). Recently, the American Broadcasting Company ( $A B C$ ) signed a $\$ 400$ million extension that guarantees the network exclusivity in broadcasting rights for the four major bowls until the year 2006 (Mitten, 2000). Due to the tremendous popularity of college football, there is an equal opportunity for revenue generation. In 1992, the Congressional Research Service estimated that exempt organizations received "\$1.1 billion in corporate sponsorship payments, of which $\$ 64$ million was paid to college football bowl organizations" (Hill, 1996, p. 1). As a result of the significant economic rewards, winning has generated competition amongst universities to recruit the top high school prospects necessary to produce winning teams (Mitten, 2000).

A major violation, as defined in the NCAA Manual (2004a), consists of all violations other than secondary violations; specifically violations that provide an extensive recruiting or competitive advantage (Bylaw 19.02.2.2).

A secondary violation is isolated or inadverant in nature, provides or
is intended to provide only a minimal recruiting, competitive or other
advantage and does not include any significant recruiting inducement
or extra benefit. Multiple secondary violations by a member
institution may collectively be considered as a major violation.
(NCAA, 2004a, Bylaw 19.02.2.1)

Research concerning NCAA major rules violations in intercollegiate athletics has focused on the effect that major violations have on total athletic department revenue and negative exposure (Davis, 1999; Goff, 2000). In examining whether or not institutions charged with a major violation are bigtime athletic programs, Davis (1999), found that at least fifty percent of the sanctioned schools do not run what would be considered big-time 
intercollegiate athletic programs. In addition, the nature of the violations for which these schools were sanctioned was widely distributed among both revenue and non-revenue producing sports (Davis). Goff (2000) found that "negative exposure due to NCAA sanctions may offset the gains made by past athletic success, but the evidence to date does not show that such negative exposure does more than negate the positive influence of past success" (p. 101).

Other research has focused on examining NCAA major rules violations in relation to rank. Otto (2000) found that the most successful NCAA Division I men's basketball programs (defined as the highest ranking programs from the ten highest ranking conferences) are investigated three times as often as the least successful programs (defined as the lowest ranking programs from the ten lowest ranking conferences).

Researchers (Byers, 1995; Funk, 1991; Gerdy, 1997) claim that the NCAA may be guilty of practicing a form of "selective enforcement." This form of selective enforcement has been defined as targeting the least successful schools for investigations while turning a blind eye to the most successful institutions because they generate a bulk of the national interest and, therefore, a bulk of the revenue (Byers). Another form of selective enforcement is based on the notion that the NCAA goes after the most successful programs because they attract the most media attention; therefore, they are more closely scrutinized (Zimbalist, 1999).

Regardless of the form of selective enforcement considered, it is safe to report that equity does not exist in NCAA enforcement. Critics (Byers, 1995; Funk, 1991; Gerdy, 1997) claim that the NCAA protects the big-time programs at the expense of the least successful programs; contrarily, researchers (Davis, 1999; Otto, 2000) have reported results that suggest that the NCAA charges big-time programs with the most major violations. While it is the case that the NCAA has charged more big-time programs with major violations than small-time programs, they still may be treated with "kid gloves." It could be the case that, while penalized more often, the penalties they receive are less severe.

\section{THE NCAA}

Founded in 1906, the NCAA is the dominant governing body of intercollegiate athletics in the United States (Yasser, 1993). The NCAA investigates and prosecutes alleged violators, and ultimately determines whether or not a member institution has committed a rule violation. The NCAA creates legislation by its members, for its members (NCAA, 2004a, 
Bylaw 5.01.1). Similar to that of the United States government "the NCAA can best be described as a hybrid of legislative, executive, and judicial bodies" (Ponticello, 1991, p. 44).

As a governing organization, NCAA rules and regulations have grown substantially in both number and scope over time (Porto, 1985). It is the responsibility of each member institution to control its intercollegiate athletics program in compliance with the rules and regulations of the Association. "The mission statement of the NCAA enforcement program is to eliminate violations of NCAA rules and impose appropriate penalties should violations occur" (NCAA, 2004a, Bylaw 19.01.1, p. 333). The program is committed to fairness pertaining to coaches, administrators, competitors, and other institutions while acting in a timely and equitable fashion (NCAA, Bylaw 19.01.1). An important consideration in imposing penalties is to provide fairness to uninvolved student-athletes, coaches, administrators, competitors and other institutions (Bylaw 19.01.1).

As a result of the NCAA's growth in power, it has transformed itself from a legislative organization, into an organization that not only creates rules but also administers and resolves disputes in relation to those rules (Porto, 1985). "Critics have charged that flaws exist in the NCAA enforcement process" (Goplerud, 1991, p. 544). Stringency in measures of control imposed by the NCAA has led institutional members, individual athletes, and other affected persons to initiate lawsuits against the Association, challenging its rules and authority (Porto, 1985).

\section{HISTORY OF VIOLATIONS}

There have been 468 major violation charges in Division I from 1953 to the present; 219 (47\%) specifically involved football (NCAA, n.d.). With nearly a majority of major violations occurring in football, there exists the problem of being a repeat violator. Southern Methodist University, for example, has been charged with eight major violations from 1953-2002. All eight of their violations (in the years 2000, 1987, 1985, 1981, 1976, 1974, 1965, and 1958) have been in the sport of football (NCAA).

In Division I-A football, from 1980-2004, there have been 91 major infractions cases, implicating 57 different member institutions. Since the NCAA began investigating institutions in 1953, the top ten major infraction offenders are as follows: Southern Methodist University, eight major violation investigations; Arizona Scate University, Texas A\&M University-College Station, and Wichita State University, seven major violation investigations; Auburn University, Florida State University, Kansas State University, 
University of California, Los Angeles, University of Minnesota, Twin Cities, and University of Wisconsin, Madison, each with six major violation investigations (NCAA, n.d.).

\section{REVENUE EXPENSE RATIO}

In its annual budget for 2000-2001, the NCAA reported generating $\$ 256.2$ million in television contract revenue, which accounted for nearly $80 \%$ of its overall revenue. Likewise, its largest expense, at $66 \%$ of its total expenses, was \$215.3 million allotted to Division I expenses (NCAA, 2000). In analyzing a summary of gross receipts (1996-2001), the NCAA reported a $7.7 \%$ increase in its ticket revenue from $1999-00(\$ 64,593,328)$ to $2000-01$ $(\$ 70,011,199)$. In $1996-97$, ticket revenue was reported at $\$ 46,944,590$, and $\$ 70,011,199$ in $2000-01$ (nearly a $60 \%$ increase over five years); the NCAA reported a similar percent increase amongst its corporate sponsorship dollars $(\$ 4,631,667$ in 1996-97 and \$7,328,616 in 2000-01) (NCAA).

Total expenditures for individual NCAA institutions at all divisional levels for the year 1997-98 ranged from $\$ 47$ million at the University of Michigan to about \$1.2 million at Kenyon and Wesleyan (Shulman \& Bowen, 2001). For nearly all universities in Division I-A football and top tier Division I men's basketball, direct revenues from football and basketball were greater than direct expenses; for at least $70 \%$ of the schools, the difference was greater than $\$ 1$ million (Goff, 2000). With millions of dollars to be had by member institutions, the rewards for winning have multiplied, and so have the sanctions for breaking rules (Byers, 1995). Coaches are under pressure from their administration and alumni to produce victories. This pressure, combined with the monetary and material rewards available to successful Division I-A coaches, are motivation enough to cause some coaches to employ any means necessary to recruit the top athletes (Funk, 1991).

\section{PAST RESEARCH}

Recent studies examined revenue generated by Division I-A football programs. Among the Division I-A schools $(n=113), 75(66 \%)$ generated a profit and $38(34 \%)$ reported a net loss (Chang \& Canode, 2002). Similarly, of Division I-A football programs analyzed $(n=112), 73(65 \%)$ generated a profit, while 39 (35\%) reported a net loss (Mondello, 2000).

Researchers (Gerdy, 1997; Hart-Nibbrig \& Cottingham, 1986; Lapchick \& Slaughter, 1994; Sack \& Staurowsky, 1998; Smith, 2000) have shown the importance of money coming from outside sources and the effect it has not 
only on a university but also on the athletic department itself. Universities and athletic departments are generating millions of dollars in revenue from football players whose talent is realized in the form of a winning football program (Carsonie, 1991; Chang \& Canode, 2002; Chu, Segrave, \& Becker, 1985; Davis, 1991; Sack \& Staurowsky; Telander, 1989). As a result of this, top athletes make it to the professional ranks of the NFL. However, in order to retain these top athletes many coaches have had to compromise abiding by the rules of the NCAA (Burke, 1982; Chu, 1989; Davis, 1999; Knight Foundation Commission on Intercollegiate Athletics, 2001; Pernell, 1991).

\section{PURPOSE OF STUDY}

The purpose of this study was to determine NCAA Division I-A football programs' $(n=113)$ odds of being charged with a major violation based on specified institutional and programmatic variables. This study reports the results of the change in the odds of the dependent variable (being a NCAA Division I-A football program charged or not charged with a major violation from 1991-2002). The researcher incorporated quantitative research in order to determine the odds of a certain event occurring (being charged with a major violation) when tested against six explanatory variables. Taken as a whole, the theory behind this research is that each NCAA member institution is characterized by many factors that affect the overall functioning of their respective athletic departments, which in turn, directly affects the odds of being charged with a major violation.

\section{Method}

Binary logistic regression was used to analyze the probabilities associated with the odds of NCAA Division I-A football programs $(n=113)$ being charged with a major violation in relation to the explanatory variables of interest. The logistic regression model estimates the probability of a certain event occurring. It calculates the changes in the log odds of the dependent variable, not actual changes in the dependent variable itself (Ramsey \& Schafer, 1997). The dependent variable, NCAA Division I-A football programs charged with a major violation from 1991-2002, was dichotomous in nature. The binary response variable "was charged with a major violation," or "not charged with a major violation;" coded 1,0 , respectively.

Four resources were used to gather information on the Division I-A football programs: 1. Sagarin rankings (2000); 2. NCAA Official Website (2004); 3. National Football League's Official Website (2004); and, 4. Equity 
in Athletics Disclosure Act (EADA) (2002). Sagarin ratings provide power and player ratings for numerous professional and collegiate sports. Sagarin ratings use difficulty of schedule and win-loss results to establish the rankings (Sagarin, 2000). Sagarin's college football rankings have proven their value to the NCAA (Sagarin, n.d.). Ratings, win-loss records, and schedule strengths are based solely on games between Division I-A teams. The schedule ratings represent the average schedule difficulty faced by each team in the games that it has played so far. The schedule difficulty of a given game takes into account the rating of the opponent and the location of the game (Sagarin, 2000). For this study, the researcher took the combined average rank for each member institution participating in NCAA Division I-A football from 19912002. After collecting all the rankings for each year and each school - from Sagarin's website - the author calculated the average.

The official website of the NCAA, http://www2.ncaa.org/, was the primary resource for information regarding all intercollegiate athletic programs who are members of the NCAA organization. Information pertaining to the following was gleaned from the site: all institutions charged with a major violation of NCAA rules in the sport of Division I-A football from 1991-2002, the specific region of the country that each program falls into (namely five, of which are: northeast, great lakes, midwest, southeast, and west), the average accumulated percent attendance capacity for all institutions participating in Division I-A football for 2001-2002, and institutions charged with major infractions in all sports (since the inception of the NCAA Enforcement department, beginning in 1953, excluding Division I-A football programs charged with a major violation from 1991-2002).

Primary information regarding National Football League draft history was found at http://www.nflreport.com/Draft_history.htm (2004). From this website the researcher obtained the total number of players from each member institution participating in Division I-A football from 1991-2002 who were drafted in the first six rounds of the NFL draft and took the combined average.

In order to obtain the percent of athletic department revenue coming from football, the researcher obtained official EADA data for the most recent year, 2001-2002. Clement (2004) highlights the significance of EADA stating,

The 1994 re-authorization of the federal government Elementary and Secondary Education Act contained a provision requiring colleges and universities to collect and disclose information concerning genderequity in intercollegiate athletics. The Equity in Athletics Disclosure component of the Act requires schools to publish male/female ratio data for school enrollment and athletic participation. Schools are required to list varsity team membership, operating and recruiting 
expenses, numbers and gender of all coaches. All student aid provided athletes, revenue generated by teams and coaching salaries are to be disclosed. These data are to be published yearly beginning in October 1996 (p. 122).

Researchers (Davis, 1999; Goff, 2000; Otto, 2000) have found that the rank is an important variable to consider when examining intercollegiate sport in relation to major violation charges. Based on such findings this researcher hypothesized that the variable rank (using the Sagarin Ratings instrument) would play a significant role in better explaining whether or not an institution is charged with a major rules violation in the sport of Division I-A football.

Research (Atwell, Grimes, \& Lopiano, 1980; Fulks, 1997; Goff, 2000; Hiestand, 1999; Schulman \& Bowen, 2001; Yasser, McCurdy, \& Goplerud, 1994) suggests that Division I-A football programs are focused on generating revenue from gate receipts from football games. Because of the importance of generating revenue, the variable "accumulated percent attendance capacity" was tested. This variable provided the amount to which each institution's football stadium was filled to its capacity. A linear relationship exists between accumulated percent attendance capacity and gate receipts; the more people in the stands, the more money generated in the form of gate receipts. Also, utilizing data gleaned from the NCAA major infractions database the variable total number of major violations over all sports over all-time at each NCAA Division I-A member institution was tested.

Researchers (Carsonie, 1991; Chu, Segrave, \& Becker, 1985; Davis, 1991; Sack \& Staurowsky, 1998; Telander, 1989) have recognized that together universities and athletic departments are generating millions of dollars in revenue from football players whose talent is realized in the form of a winning football program. As a result, some of the top athletes from the "powerhouse" football programs make it to the professional ranks of the NFL. However, in order to sign these top athletes many coaches have had to compromise abiding by the rules of the NCAA (Burke, 1982; Chu, 1989; Davis, 1999; Knight Foundation Commission on Intercollegiate Athletics, 2001; Pernell, 1991). Based on the relationship between possible violations of NCAA rules broken in order to recruit the top football players in the country, the variable of total number of players each football program has had drafted in the first six rounds of the NFL from 1991-2002 was also considered.

Based on the NCAA reports of Alabama and Kentucky (NCAA Division I Committee on Infractions, 2002a \& 2002b) and Reeves (2002) findings pertaining to specific conferences, this researcher proposes to test whether or not region of the country (northeast, southeast, midwest, west, or great lakes) 
effected the probability of a Division I-A football program being charged with a major violation of NCAA rules.

The researcher tested the effect that six independent variables had on the dependent variable. Five of the six explanatory variables were continuous in nature, namely, (1) Sagarin rankings; (2) percent of athletic department revenue from football; (3) number of players drafted into the NFL; (4) number of major violations in all sports, over all-time; and, (5) average accumulated percent attendance capacity. One variable, region, was categorical and nominal in nature. Region was dummy coded utilizing $k-1$ design variables, where $\mathrm{k}$ is the number of levels of the nominal scale variable. Region had five levels; therefore, it consisted of four design variables. A .05 alpha level was used to designate statistical significance.

\section{RESULTS}

Descriptive statistics revealed that of the 113 subjects $28(25 \%)$ were charged with a major violation of NCAA rules from 1991-2002 and $85(75 \%)$ subjects were not. In relation to rank, nearly $40 \%$ of the subjects charged with a major violation yielded a Sagarin ranking between $1-25$; while $36 \%$ ranked between $26-50$ (75\% yielded a cumulative frequency ranking between 1 $50)$.

The number of major violations in all sports, excluding football violations from 1991-2002, ranged from zero to seven. Of the subjects charged with a major violation in football $(n=28)$, one subject was charged with seven total major violations, three subjects were charged with six major violations, five subjects were charged with five major violations, four subjects were charged with four major violations, and five subjects were charged with three major violations. Of subjects charged with a major violation over $20 \%$ had an accumulated attendance capacity of $100 \%$ or greater, and $46 \%$ had an accumulated attendance capacity between 90 and $99 \%$.

Of the 28 subjects charged with a major violation of NCAA rules, 12 out of $29(41 \%)$ were in the southeast region, six out of $27(22 \%)$ were in the midwest region, four out of $27(18 \%)$ were in the west region, three out of 21 $(14 \%)$ were in the great lakes region, and two out of $9(22 \%)$ were in the northeast region of the country.

In relation to total number of players drafted in the NFL in the first six rounds, $32 \%$ of subjects charged with a major violation sent 40 or more players to the NFL ( 40 - 67 total players drafted); $25 \%$ of subjects charged with a major violation sent between 30 - 39 players to the NFL, and $11 \%$ of 
subjects charged with a major violation sent between $20-29$ players to the NFL.

One quarter of subjects charged with a major violation yielded total revenue coming from football of $70 \%$ or greater; 21 yielded total revenue coming from football between 50 and $60 \%$; and, 12 out of $28(43 \%)$ yielded total revenue coming from football between 30 and $59 \%$.

Prior to running the binary logistic regression the researcher analyzed bivariate scatterplots for all continuous independent variables. Examination of the scatterplots revealed trends of multicollinearity amongst some the variables. Highly correlated explanatory variables pose a problem, namely by decreasing the precision of the individual estimated coefficients (Ramsey \& Schafer, 1997).

Inflated variances of estimated coefficients mean wider confidence intervals and a diminished ability of tests to find significant results. Besides leading to inflated variances multicollinearity has several related consequences: (1) The variances of predicted values will also be inflated. (2) The chance of having influential observations will be greater. (3) The effects of measurement errors in any of the explanatory variables will be more severe (Ramsey \& Schafer, p. 334).

After having run scatterplots on the independent variables, the relationship between the explanatory variables was more closely analyzed by running Pearson correlations. The following four independent variables posed a multicollinearity problem: Sagarin rankings, number of players drafted into the NFL, average accumulated percent attendance capacity, and percent of athletic department revenue from football. High Pearson correlations between the following bivariate combinations existed: Sagarin rankings and number of NFL players (-.829), Sagarin rankings and average attendance capacity ($.728)$, Sagarin rankings and percent revenue from football (-.655), number of NFL players and percent revenue from football (.673), number of NFL players and average attendance capacity (.574), and attendance capacity and percent revenue from football (.561). Based on the Pearson correlations, the variable number of major violations in all sports did not present a problem of multicollinearity.

The four multicollinear variables were transformed into standardized zscores. Because the Sagarin rankings variable was an inverse variable (as a football program wins more games, its Sagarin ranking decreases toward one) the transformed $z$-scores resulted in negative numerical values. As a result of 
the negative output, the researcher multiplied each subjects z-score by $(-1)$ making the Sagarin rankings variable positive.

After having transformed the variable scores to z-scores, the researcher computed, by summation, all four variables and created a new variable that incorporated the data from all four existing variables. The new variable, 'powerhouse,' got its name based on what it represented, namely NCAA Division I-A football programs who perennially rank high (toward a number one Sagarin ranking), send a high number of players to the NFL, have their stadiums packed to capacity for every game, and who generate a majority of their athletic department revenue from football.

With the remaining variables (region, number of major violations in all sports, and the newly combined variable, "powerhouse") two analyses were run. The first included the variable number of major violations in all sports and "powerhouse" and the second analysis included number of major violations in all sports, 'powerhouse,' and region. Results from the binary logistic regression analysis yielded a significant p-value for total number of major violations in all sports and "powerhouse" $(\mathrm{p}<.05)$ (see Table 1). Results from the Cox \& Snell r square and Nagelkerke $r$ square for the model summary were .239 and .355 respectively.

Significant relationships found between the above mentioned variables allowed for the results of the $\operatorname{Exp}(B)$ to be interpreted. $\operatorname{Exp}(B)$ is the actual odds ratio; it is the ratio of relative importance of the independent variables in terms of the effect on the dependent variable's odds. When $\operatorname{Exp}(\mathrm{B})$ is $<1$, increasing values of the variable correspond to decreasing odds of the events occurrence; when $\operatorname{Exp}(\mathrm{B})$ is $>1$, increasing values of the variable correspond to increasing odds of the events occurrence (Ramsey \& Schafer, 1997).

$\operatorname{Exp}(\mathrm{B})$ for the variable number of major violations in all sports was 1.320 ; as the number of major violations in all sports increases by one unit, the odds of NCAA Division I-A football programs being charged with a major violation increases by a factor of 1.320 . $\operatorname{Exp}(\mathrm{B})$ for the variable "powerhouse" was 1.422. Recall that the "powerhouse" variable is a summation of standardized scores of Sagarin rankings, numbers of players drafted into the NFL, average attendance capacity, and percent of revenue from football. Therefore, as the "powerhouse" variable increases by one unit in all four component areas these "powerhouse" programs are actually experiencing a $5.688(4 * 1.422)$ increase in the odds of being charged with a major violation (see Table 1). 


\section{TABLE 1}

Results of the Binary Logistic Regression for Number of Major Violations in All sports and "powerhouse" against the Dependent Variable

Variable B S.E. Wald d.f. $\quad$ Sig. $\operatorname{Exp}(\mathrm{B})$

Major Violations .278 .138 4.046 $1 \quad .044^{*}$ in all sports

"powerhouse" .352 .08816 .153

$1 \quad .000^{* *} \quad 1.422$

*sig. at .05 level, ** sig. at .01 level

An analysis of the classification table for the dependent variable and number of major violations in all sports and "powerhouse" revealed that the model correctly predicted $89.4 \%$ of subjects not charged with a major violation and it correctly predicted $50.0 \%$ of the subjects charged with a major violation (see Table 2).

\section{TABLE 2}

Classification Table for Subjects charged or not charged with a Major Violation when the variables Number of Major Violations in All sports and "powerhouse" ure included in the model

$$
\begin{array}{lrr}
\multicolumn{2}{c}{\text { Predicted }} & \text { Percent (\%) Correct } \\
\text { No MV } & \text { MV } &
\end{array}
$$

Observed

No MV

76

9

89.4

MV

14

14

50.0

Results from the Cox \& Snell r square and Negelkerke r square for the model summary were .239 and .355 respectively. 
Finally, the researcher ran number of major violations in all sports, 'powerhouse,' and the categorical variable, region. Results from the binary logistic regression analysis yielded a significant result for total number of major violations in all sports and "powerhouse" $(\mathrm{p}<.05)$ (see Table 3). Results from the Cox \& Snell $\mathrm{r}$ square and Nagelkerke $\mathrm{r}$ square for the model summary were .253 and .376 respectively.

$\operatorname{Exp}(\mathrm{B})$ for the variable number of major violations in all sports was 1.399; as the number of major violations in all sports increases by one unit, the odds of NCAA Division I-A football programs being charged with a major violation increases by 1.399 units. $\operatorname{Exp(B)}$ for the variable, "powerhouse" was 1.404; this is to say, as a subjects Sagarin rankings decreases (improves) by one unit; and number of players drafted into the NFL, average attendance capacity, and percent of revenue from football increases by one unit; the odds of NCAA Division I-A football programs being charged with a major violation increases by $5.616(1.404 * 4)$ units (see Table 3$)$.

\section{TABLE 3}

Results of the Binary Logistic Regression for Number of Major Violations in All sports, "powerhouse" and Region against the Dependent Variable

\begin{tabular}{lcccccc} 
Variable & B & S.E. & Wald & d.f. & Sig. & $\operatorname{Exp(B)}$ \\
\hline $\begin{array}{l}\text { Major Violations } \\
\text { in all sports }\end{array}$ & .336 & .157 & 4.565 & 1 & $.033^{*}$ & 1.399 \\
"powerhouse" & .339 & .093 & 13.329 & 1 & $.000^{* *}$ & 1.404 \\
West & -.559 & .722 & .598 & 1 & .439 & .572 \\
Greatlakes & -.961 & .851 & 1.277 & 1 & .258 & .382 \\
Northeast & .418 & 1.041 & .161 & 1 & .688 & 1.519 \\
Midwest & -.511 & .731 & .490 & 1 & .484 & .600
\end{tabular}

*sig. at .05 level, ${ }^{* *}$ sig. at .01 level

An analysis of the classification table for the dependent variable and number of major violations in all sports, "powerhouse", and region revealed 
that the model correctly predicted $88.2 \%$ of subjects not charged with a major violation and is correctly predicted $46.4 \%$ of the subjects charged with a major violation (see Table 4).

\section{TABLE 4}

Classification Table for Subjects charged or not charged with a Major Violation when the variables Number of Major Violations in All sports, "powerhouse" and Region are included in the model

\begin{tabular}{|c|c|c|}
\hline \multirow{2}{*}{\multicolumn{2}{|c|}{\begin{tabular}{c}
\multicolumn{2}{c}{ Predicted } \\
o MV MV
\end{tabular}}} & Percent (\%) Correct \\
\hline & & \\
\hline
\end{tabular}

Observed

$\begin{array}{llll}\text { No MV } & 75 & 10 & 88.2 \\ \text { MV } & 15 & 13 & 46.4\end{array}$

Overall Percentage

77.9

\section{DISCUSSION}

Results of this study show that programs classified as "powerhouse" are charged with more major violations and have over 5.5 times the odds of being charged with a major violation than 'non-powerhouse' programs. One potential explanation for these results could be that football programs classified as "powerhouse" assume a high level of national visibility and media attention and therefore are more closely scrutinized. In brief, football programs classified as "powerhouse" from 1991-2002 yielded the following results: $75 \%$ ranked in the top $50,82 \%$ committed two or more major violations in all sports, $68 \%$ reported an accumulated percent attendance capacity of 90 or greater, $61 \%$ were in the southeast or midwest region of the country, $57 \%$ had 31 or more players drafted in the NFL's first six rounds, and $75 \%$ generated 40 or more of their total percent athletic department revenue from football.

It is also interesting to note that 13 out of $28(46 \%)$ of the subjects charged with a major violation committed four or more major violations in all sports. 
The University of Kentucky, for example, has been charged with seven major violations from 1953-2002; three of which have been in the sport of football, the other four violations in men's basketball (1989, 1988, 1976, and 1953) (NCAA Division I Committee on Infractions, 2002a). In Kentucky's case, it is clear that the two sports programs charged with major violations have been football and men's basketball. Perhaps all programs are committing major violations, but because of their visibility and ability to generate revenue, football and men's basketball are the programs most closely scrutinized.

Based on the NCAA's Public Infraction Reports of Alabama and Kentucky (NCAA Division I Committee on Infractions, 2002a \& 2002b) and Reeves (2002) findings pertaining to specific conferences, the researcher reported results in relation to region of the country. Since 1953, the Southeastern Conference (SEC) has been charged with 42 major violations, the Pacific-10 Conference with 36 major violations, and the Big-10 with 34 major violations. While the SEC possesses the most major rules violations, they are also known for winning - "The SEC has won 72 national titles in the last decade, averaging more than seven a year in its 20 sports" (Reeves, 2002, p. 5C).

Out of a total of 28 major violations from 1991-2002, 21 (75\%) had an overall Sagarin ranking average of $1-50$. Fifty-three percent of subjects charged with a major violation were ranked in the top 50 and hailed from the southeast region of the country. Results of this study seem to suggest that football programs located in the southeast region of the country, that possessed a top Sagarin ranking and generated a majority of their total athletic department revenue from, football were more often charged with major violations of NCAA rules than those in other regions. It may be that the Division I-A football programs in the southeast region of the country adhere to different sets of organizational norms than the rest of the country. To members in the southeast region, such norms could be seen as an acceptable deviation from the norm; whereas, other regions of the country might perceive such actions as negative deviance. Based on an ordinal rank, $41 \%$ of subjects in the southeast region were charged with a major violation, $28 \%$ coming from the top 25 alone. The southeast region doubled both the midwest and west regions in total number of major violations, quadrupled the greatlakes region, and sextupled the northeast.

Of the 18 subjects who had an attendance capacity of $100 \%$ or greater, $33 \%$ were charged with a major violation, and of the 45 subjects who had an attendance capacity of $90 \%$ or greater, $42 \%$ were charged with a major violation of NCAA rules.

Since there are programs that are willing to compromise the rules of the NCAA in order to obtain these players services, an internal competition 
amongst football programs exists. If this were the case, the results of this study would suggest that the southeast region of the country has been willing to compromise the rules of the NCAA to a greater extent than any other region of the country. Nevertheless, it is just as plausible that all football programs, in all regions of the country are willing to do whatever it takes to attract and retain top athletes and it just so happens that football programs in the southeast region are being caught more often.

Researchers (Gerdy, 1997; Hart-Nibbrig \& Cottingham, 1986; Lapchick \& Slaughter, 1994; Sack \& Staurowsky, 1998; Smith, 2000) have shown the importance of money coming from outside sources and the effect it has, not only on a university, but also on the athletic department itself. Of the 28 subjects charged with a major violation of NCAA rules, seven out of $28(25 \%)$ yielded total revenue coming from football of $70 \%$ or greater; 13 out of 28 $(46 \%)$ had $50 \%$ or greater of their total revenue coming from football. What is of interest is that nearly half $(46 \%)$ of the programs charged with a major violation generated at least $50 \%$ of their total revenue from football.

Drawing on the work of Davis (1999), Gerdy (1997) and Smith (2000) it has been hypothesized that generating the greater part of revenue from athletic departments football programs would cause the odds of being charged with a major violation to increase. These data offered support for this hypothesis. Findings may possibly indicate that institutional pressures placed upon athletic administrators and coaches, whose athletic departments are generating the bulk of their revenue from football, are so great that in order to continue to generate such revenue they feel obligated to employ any means (which equates to committing major violations) necessary in order to achieve their goal.

Based on the research of Reeves (2002), "being a top rule breaker pays off, not only in the form of national championships but also in the form of revenue generation" (p. 5C). It appears that being a "powerhouse" football program (which equates to having a low national Sagarin ranking, sending a lot of players to the NFL, generating a high percentage of revenue from football, and filling stadiums to capacity) does not deter subjects from committing major violations. On the contrary, the "powerhouse" football programs are, in fact, charged with the greatest number of major violations.

The NCAA and its members should be aware that institutions classified as "powerhouse" football programs have over 5.5 times the odds of being charged with a major violation of NCAA rules than programs classified as 'non-powerhouse.' Results of this study seem to support a particular notion of 'selective enforcement' - the notion that the NCAA goes after the most successful programs because they attract the most media attention; therefore, they are more closely scrutinized (Zimbalist, 1999). 
The NCAA and its members ought to be cognizant of the fact that "powerhouse" football programs get charged with more major violations than do 'non-powerhouse' programs. The NCAA and its members should be mindful that the penalties that universities, athletic departments, and football programs receive for committing major violations do not seem to deter them from committing more. The NCAA must recognize that the benefits of being a "powerhouse" football program seem to far outweigh the cost of being charged with a major violation.

\section{ABOUT THE AUTHOR}

Kadence Alexa Otto, Ph. D. is an Assistant Professor in the Western Carolina University Sport Management Program. Her research interests focus on due process, state action, and unethical conduct in college athletics. Dr. Otto earned her Ph. D. from Florida State University.

\section{REFERENCES}

Atwell, R.H., Grimes, B., \& Lopiano, D.A. (1980). The money game: Financing collegiate athletics. Washington, D.C.: American Council on Education.

Burke, C.B. (1982). American collegiate populations: A test of the traditional view. New York, NY: New York University.

Byers, W. (1995). Unsportsmanlike conduct. USA: The University of Michigan.

Carsonie, F.W. (1991). Educational values: A necessity for reform of big-time intercollegiate athletics. Capital University Law Review, 20, 661-690.

Chang, S., \& Canode, S. (2002). Economic impact of a future college football program. Journal of Sport Management, 16, 239-246.

Chu, D. (1989). The character of American higher education and intercollegiate sport. New York, NY: State University of New York.

Chu, D., Segrave, J.O., \& Becker, B.J. (1985). Sport and higher education. Champaign, IL: Human Kinetics.

Clement, A. (2004). Law in sport and physical activity (3rd ed.). Miami Shores, FL: Sport and Law.

Davis, R.N. (1991). Athletic reform: Missing the bases in university athletics. Capital University Law Review, 20, 597-609. 
Davis, T. (1999). Sports law in the 21st century: Intercollegiate athletics in the next millennium: A framework for evaluating reform proposals. Marquette Sports Law Journal, 9, 1-20.

Equity in Athletics Disclosure Act, Pub. L. No. 103-382, 108 Stat. 3969 (2004).

Fulks, D.L. (2001). Revenues and expenses of Divisions I and II intercollegiate athletics programs: Financial trends and relationships- 2001. Indianapolis, IN: NCAA.

Funk, G.D. (1991). Major violation: The unbalanced priorities in athletics and academics. Champaign, IL: Leisure.

Gerdy, J.R. (1997). The successful college athletic program. Phoenix, Arizona: The Oryx.

Goff, B. (2000). Effects of University athletics on the University: A review and extension of empirical assessment. Journal of Sport Management, 14, 85104.

Goplerud, P.C. (1991). NCAA enforcement process: A call for procedural fairness. Capital University Law Review, 20, 543-560.

Hart-Nibbrig, N., \& Cottingham, C. (1986). The political economy of college sports. Lexington, MA: D. C. Heath and Company.

Hiestand, M. (1999). CBS keeps NCAA men's tournament [On-line]. USA Today, 1-2. Available: http://www.usatoday.com/sports/basketba/skm/skmfs 23.htm.

Hill, F.R. (1996). Corporate sponsorship in transactional perspective: General principles and special cases in the law of tax exempt organizations. University of Miami Entertainment and Sports Law Review, 13(5), 1-70.

Knight Foundation Commission on Intercollegiate Athletics (2001, June). A call to action: Reconnecting college sports and higher education. Charlotte, NC:

Commission on Intercollegiate Athletics.

Lapchick, R.E., \& Slaughter, J.B. (1994). The Rules of the game: Ethics in college sports. Phoenix, AZ: American Council on Education and The Oryx.

Mitten, M.J. (2000). Applying antitrust law to NCAA regulation of "big time" college athletics: The need to shift from nostalgic 19th century ideals of amateurism to the economic realities of the 21st century. Marquette Sports Law Journal, 11, 2-7.

Mondello, M.J. (2000). A financial analysis of Division I-A athletic programs. International Journal of Sport Management, 1, 37-55. 
National Collegiate Athletic Association (n.d.). Major infractions case search. Retrieved January 7, 2005, from https://goomer.ncaa.org/wdbctx/ LSDBi/LSDBi.MajorInfPackage.MI_Search_Input?p_Cmd=Go_Search.

National Collegiate Athletic Association (2004a, July). 2004-2005 NCAA Division I manual. Indianapolis, IN: NCAA.

National Collegiate Athletic Association (2004b, March 25). National Collegiate Athletic Association-Frequently asked questions of the enforcement staff. Retrieved December 1, 2004, from http://www.ncaa.org/enforcement/ faq enforcement.html.

NCAA Division I Committee on Infractions (2002a, January 31). University of Kentucky public infractions report. Infractions Report No.192 Indianapolis, IN: NCAA.

NCAA Division I Committee on Infractions (2002b, February 1). University of Alabama, Tuscaloosa public infractions report. Infractions Report No. 193. Indianapolis: IN, National Collegiate Athletic Association.

National Collegiate Athletic Association (2000). NCAA Annual Budget, 20002001. Indianapolis, IN: NCAA.

National Football League (2004). NFL draft history. Retrieved December 1, 2004, from http://www.nflreport.com/Draft_history.htm.

Otto, K.A. (2000). An analysis of NCAA division I men's basketball rankings, investigations, infractions, and penalties from 1990-1999. Unpublished master's thesis, The Florida State University, Tallahassee, Florida, United States of America.

Pernell, L. (1991). A commentary on professor Goplerud's article, "NCAA enforcement process: A call for procedural fairness." Capital University Law Review, 20, 561-566.

Ponticello, B.W. (1991). 'Over' due process: The saga of the NCAA, its members and their representatives. Lincoln Law Review, 20, 43-69.

Porto, B.L. (1985). Legal and constitutional challenges to the NCAA: The limits of adjudication in intercollegiate athletics. In A.T. Johnson \& J.H. Frey (Eds.), Government and sport: The public policy issues (pp. 117-136). Totowa, NJ: Rowan \& Allanheld.

Ramsey, F.L., \& Schafer, D.W. (1997). The statistical sleuth. Belmont, CA: Wadsworth.

Reeves, J. (2002, February 10). Alabama, Kentucky add to league's record number of major violations. The Tallahassee Democrat, p. 5C. 
Sack, A.L., \& Staurowsky, E.J. (1998). College athletes for hire: The evolution and legacy of the NCAA's amateur myth. Westport, CT: Praeger.

Sagarin, J. (n.d.). Meet Jeff Sagarin. Retrieved December 2, 2004, from http:/www.kiva.net/ jsagarin/p2wjeff.htm .

Sagarin, J. (2000). Jeff Sagarin's NCAA football ratings-Final 2000 college football rankings. USA Today [On-line], 1-4. Retrieved January 11, 2005, from http://www.usatoday.com/sports/sagarin/fbt00.htm.

Shulman, J.L., \& Bowen, W.G. (2001). The game of life: College sports and educational values. Princeton, NJ: Princeton University.

Smith, R.K. (2000). A brief history of the National Collegiate Athletic Association's role in regulating intercollegiate athletics. Marquette Sports Law Review, 11, 9-22.

Telander, R. (1989). The hundred yard lie: The corruption of college football and what we can do to stop it. New York, NY: Simon and Schuster.

Yasser, R. (1993). A comprehensive blueprint for the reform of intercollegiate athletics. Marquette Sports Law Journal, 3, 123-159.

Yasser, R., McCurdy, J. \& Goplerud, P. (1994). Amateur sports associations rights, rules, procedures, etc. In Sport law: cases and materials (2nd ed., pp. 47-54). Cincinnati, OH: Anderson.

Zimbalist, A. (1999). Unpaid professionals. Princeton, NJ: Princeton University. 